Article

\title{
Preliminary Investigation of Pharmacist-Delivered, Direct-to-Provider Interventions to Reduce Co-Prescribing of Opioids and Benzodiazepines among a Medicare Population
}

\author{
Jennifer M. Bingham ${ }^{1} * \mathbb{C}$, Ann M. Taylor ${ }^{2}$, Kevin P. Boesen ${ }^{1}$ and David R. Axon ${ }^{2} \mathbb{D}$ \\ 1 Tabula Rasa HealthCare, Moorestown, NJ 08057, USA; kboesen@trhc.com \\ 2 Pharmacy Practice and Science, University of Arizona College of Pharmacy, Tucson, AZ 85721, USA; \\ taylor@pharmacy.arizona.edu (A.M.T.); axon@pharmacy.arizona.edu (D.R.A.) \\ * Correspondence: JBingham@trhc.com; Tel.: +1-520-955-8587
}

Received: 27 January 2020; Accepted: 18 February 2020; Published: 21 February 2020

check for updates

\begin{abstract}
Co-prescribing of opioids and benzodiazepines can lead to overdoses and mortality. This retrospective study analyzed prescription claims data collected in 2016. A national medication therapy management (MTM) program conducted prescriber-based outreach interventions for patients with concurrent opioid and benzodiazepine prescriptions. The pharmacist's direct-to-prescriber intervention was conducted following a targeted medication review. The pharmacist initiated interventions with the prescriber via facsimile to recommend discontinuation of concurrent use of these drugs. This study included 57,748 subjects who were predominantly female $(67.83 \%)$ and aged $\geq 65$ years $(66.90 \%)$. Prescribers were most commonly located in the southern United States $(46.88 \%)$. The top prescribed opioid medications were hydrocodone-acetaminophen (33.60\%), tramadol (17.50\%), and oxycodone-acetaminophen (15.66\%). The top benzodiazepines prescribed concurrently with opioids were alprazolam (35.11\%), clonazepam (21.16\%), and lorazepam (20.09\%). Based on the pharmacists' recommendations, 37,990 (65.79\%) resulted in a medication discontinuation (benzodiazepines $40.23 \%$; opioids $59.77 \%$ ) by the provider. There were significant differences in the proportion of opioids discontinued by subject age $(p<0.001)$ and prescriber geographical region $(p=0.0148)$. The top medications discontinued by the prescriber were hydrocodone-acetaminophen $(18.86 \%)$, alprazolam $(14.19 \%)$, and tramadol $\mathrm{HCl}(13.51 \%)$. This study provides initial evidence for pharmacist-supported, direct-to-prescriber programs as an effective medication safety strategy.
\end{abstract}

Keywords: opioid; benzodiazepine; pharmacist delivered; co-prescribing

\section{Introduction}

Opioid use rates have doubled (from $4.1 \%$ to $9.0 \%$ ) among older adults (65 years and older) in the United States (US) in recent years [1]. As a result, there are more opioid-related problems (e.g., addiction, adverse drug events), with deaths increasing by 345\% between 2001 and 2016 [2]. While the recent opioid crisis has heightened awareness among the medical community, policy makers, and the general public [3,4], co-prescribing of opioids and benzodiazepines remains widespread. This is particularly concerning given the potential for associated adverse drug events, morbidity, and mortality [5]. Recently, the Centers for Disease Control and Prevention released guidelines specifically aimed at reducing overprescribing of opioids and avoiding concurrent use of opioids and benzodiazepines (potentiator drugs) [6]; potentiator drugs enhance the effects of an opioid medication when taken concurrently and may cause serious problems [7,8]. The magnitude of co-prescribing of these two drugs is an ongoing problem, and thus, it must remain a top priority in the healthcare arena. 
Primary care providers (PCPs) typically are the first to intervene with patients, prescribing approximately $50 \%$ of all opioids [9]. However, many PCPs find it difficult to manage these patients given the complexity of their cases and limited knowledge regarding available resources (e.g., prescribing guidelines, pain scales) [9].

To this end, pharmacists are in a unique position, given their extensive clinical training in medication management and identifying medication-related problems (e.g., drug-drug interactions, dosing concerns, drug-disease interactions, adverse drug events (ADEs), monitoring concerns, and therapeutic duplication avoidance) to help address inappropriate use of opioids $[10,11]$, and concurrent use of opioids and benzodiazepines via medication therapy management (MTM) [12]. Additionally, pharmacists play an integral role in mitigating these avoidable opioid-related drug interactions. [13] Pharmacist-delivered MTM services comprise a compendium of services designed to optimize health outcomes and reduce ADEs, including those associated with concurrent use of opioids and benzodiazepines [11,14].

Previous studies have investigated the outcomes associated with pharmacist-delivered, direct-to-provider interventions in reducing use of potentially inappropriate medications (PIMs) [10,15]. Monane et al. found that a pharmacist-delivered, telephonic (telehealth) prescriber intervention was successful in reducing the prescribing of PIMs in the elderly (e.g., Beers List) [14]. Another direct-to-provider intervention study decreased opioid utilization for chronic pain, improved adherence to guidelines, and showed a significant decrease in co-prescribing of opioids with benzodiazepines [10].

Yet, little is still known about the impact of pharmacist-delivered MTM interventions, specifically addressing co-prescribing of opioids and benzodiazepines. To address this gap, the study objectives were to describe the: (1) number of pharmacist-delivered MTM interventions to reduce co-prescribing of opioids and benzodiazepines; (2) most commonly co-prescribed opioids and benzodiazepines; and (3) number of and differences in primary care provider-accepted recommendations based on patient age, gender, and prescriber region over a one-year period.

\section{Materials and Methods}

\subsection{Study Design and Data Source}

This descriptive study involved a retrospective review of prescription claims data, provided by a national MTM sponsor during the period between 1 January to 31 December 2016. This project was approved by the University of Arizona Institutional Review Board.

\subsection{Study Participants}

Subjects identified in the dataset were included if they: received a telephonic, targeted medication review (TMR), were 18 years of age or older, and taking one opioid and one benzodiazepine concurrently.

\subsection{Pharmacist-Delivered, Direct-to-Provider Interventions}

A national MTM sponsor, housed at a dedicated, academic site, conducted automated TMRs to identify patients with concurrent prescriptions for opioids and benzodiazepines; as part of the TMR, the telepharmacist recommended discontinuing one of the co-prescribed drugs, using a standardized, call script designed to help maintain consistency in patient messaging. This automated TMR process used computerized algorithms to determine simultaneous fill dates and day supplies of medications in the two drug classes. The algorithm triggered "autoalerts" that were reviewed by pharmacy staff and authorized by a clinical telehealth pharmacist. If a provider intervention was deemed appropriate, a recommendation was delivered to the patient's prescriber(s) via facsimile. These interventions focused on recommendations evaluating the patient's safety risks associated with co-prescribed opioids and benzodiazepines. Pharmacy claims data were reviewed for 120 days following the intervention and deemed successful if the medication combination was not dispensed during that timeframe (e.g., discontinuation of at least one of these drug). 


\subsection{Data Collection and Analysis}

Deidentified data were extracted from the prescription claims database for the 2016 calendar year. Variables of interest included: patient age and gender; provider geographic location; name and quantity of opioid medications prescribed; name and quantity of benzodiazepine medications prescribed; number and type of pharmacist-to-provider recommendations made to reduce co-prescribing of opioids and benzodiazepines; name and number of opioid and benzodiazepine medication(s) discontinued. Descriptive statistics and chi-square tests were computed using SAS v9.4 (Cary, NC, USA). An alpha value of 0.05 was selected a priori. Post-hoc chi-square tests were conducted to assess differences between regions, and a Bonferroni correction $(p=0.05 / 6=0.0083)$ was applied.

\section{Results}

\subsection{Sample Characteristics}

The study sample consisted of 57,748 subjects who were concurrently co-prescribed an opioid and benzodiazepine. Approximately two-thirds of the study sample were female (67.83\%) and aged 65 years or older $(66.90 \%)$. Prescribers were most commonly located in the southern region $(46.88 \%)$, followed by midwestern (28.93\%), northeastern (17.06\%) and western (7.13\%) regions of the US (See Table 1).

Table 1. Demographic characteristics of study subjects co-prescribed an opioid and a benzodiazepine medication $(N=57,748)$.

\begin{tabular}{cccc}
\hline \multicolumn{2}{c}{ Characteristic } & $N$ & $\%$ \\
\hline Gender & & & \\
& Female & 39,170 & 67.83 \\
& Male & 18,578 & 32.17 \\
\hline Age, Years & $<65$ & 19,115 & 33.10 \\
& 65 or older & 38,633 & 66.90 \\
\hline Geographical Region of Prescriber & & \\
& Northeast & 9853 & 17.06 \\
& Midwest & 16,705 & 28.93 \\
& South & 27,073 & 46.88 \\
& West & 4115 & 7.13 \\
\hline
\end{tabular}

\subsection{Most Commonly Co-Prescribed Medications}

The top five opioid medications co-prescribed with benzodiazepines were hydrocodone-acetaminophen $(n=19,401,33.60 \%)$, tramadol HCL $(n=10,107,17.50 \%)$, oxycodone-acetaminophen $(n=9045,15.66 \%)$, oxycodone HCL $(n=5349,9.26 \%)$, and acetaminophen-codeine $(n=2640,4.57 \%)$. Table A1 provides the full list of concurrently prescribed opioid medication with benzodiazepine medications.

The top five benzodiazepine medications co-prescribed with opioids were alprazolam $(n=20,275$, $35.11 \%)$, clonazepam $(n=12,222,21.16 \%)$, lorazepam $(n=11,599,20.09 \%)$, diazepam $(n=6988$, $12.10 \%)$, and temazepam $(n=4233,7.33 \%)$. Table A2 provides the full list of concurrently prescribed benzodiazepine medications with opioid medications.

\subsection{Recommendations Made and Accepted}

For each subject, the clinical pharmacist made a direct-to-provider recommendation via facsimile to discontinue one of the medications. A total of 37,990 medications were discontinued, including opioids ( $n=22,708,59.77 \%)$ and benzodiazepines $(n=15,282,40.23 \%)$, resulting in a $65.79 \%$ prescriber acceptance rate of pharmacists' recommendations. Subjects whose prescribers accepted the pharmacist's 
deprescribing recommendation were similar to the overall sample for females $(n=26,067$ of 37,990, $68.6 \%$ versus $n=31,970$ of $57,748,67.83 \%$ ) and those 65 or older ( $n=27,063$ of $37,990,71.2 \%$ versus $n=38,633$ of $57,748,66.90 \%$ ). Significant differences were observed in the proportion of opioids discontinued based on subject age $(p<0.001)$ and geographical region of prescriber $(p=0.0148)$ (see Table 2).

Table 2. Demographic characteristics of study subjects whose prescriber accepted the pharmacist recommendation to discontinue an opioid or benzodiazepine $(n=37,990)$.

\begin{tabular}{|c|c|c|c|c|}
\hline Characteristic & Total $N$ & Opioid $n(\%)$ & Benzodiazepine $n(\%)$ & $p$ Value \\
\hline Total & & 22,708 (59.77) & $15,282(40.23)$ & \\
\hline Gender & & & & 0.2250 \\
\hline Female & 26,067 & $15,635(59.98)$ & $10,432(40.02)$ & \\
\hline Male & 11,923 & $7073(59.32)$ & $4850(40.68)$ & \\
\hline Age, years & & & & $<0.0010$ \\
\hline$<65$ & 10,927 & $6146(56.25)$ & $4781(43.75)$ & \\
\hline 65 or older & 27,063 & $16,562(61.20)$ & $10,501(38.80)$ & \\
\hline Geographical region of prescriber & & & & 0.0148 \\
\hline Northeast & 6804 & $4171(61.30)$ & $2633(38.70)$ & \\
\hline Midwest & 10,965 & $6540(59.64)$ & $4425(40.36)$ & \\
\hline South & 17,270 & $10,282(59.54)$ & $6988(40.46)$ & \\
\hline West & 2948 & $1713(58.11)$ & 1235 (41.89) & \\
\hline
\end{tabular}

Note: Post-hoc analyses indicated a significant difference between Northeast and West regions $(p=0.0031)$. There was no difference between the other regions $(p>0.0083)$.

The top five medications discontinued by the prescriber in response to recommendations made by the clinical pharmacist to reduce co-prescribing of opioid and benzodiazepines were hydrocodone-acetaminophen $(n=7165,18.86 \%)$, alprazolam $(n=5390,14.19 \%)$, tramadol $\mathrm{HCl}$ $(n=5131,13.51 \%)$, lorazepam $(n=35479.34 \%)$, and oxycodone-acetaminophen $(n=33658.86 \%)$. Table A3 lists the medications discontinued by prescribers to reduce co-prescribing of these two drugs.

\section{Discussion}

This descriptive study highlights commonly co-prescribed opioid and benzodiazepine medications, identified in a prescription claims database. It also provides preliminary evidence to suggest that pharmacist direct-to-provider interventions, following an MTM consultation, may help in reducing co-prescribing of opioids and benzodiazepines.

Provider acceptance $(65.79 \%)$ of pharmacist interventions, was higher than some rates previously reported [15-17]. Interestingly, Perera et al. found that pharmacist-delivered provider interventions communicated via facsimile had reported lower provider acceptance rates, particularly those related to guideline adherence and safety concerns [17]. An evaluation of recommendations made by MTM pharmacists, as part of an interprofessional chronic care management program, found that $37.5 \%$ $(N=200)$ of recommendations were accepted by providers [15]. Others have reported acceptance rates ranging from $42 \%$ to $60 \%$ in a community pharmacy setting and an average of $47 \%$ in a telehealth setting $[16,17]$. While the current study acceptance rate is higher compared to other interventions and practice settings, opportunities for improvement remain. The reasons for the somewhat higher provider acceptance rate in the current study are unknown. However, several potential explanations include subject characteristics, greater recognition of the value of pharmacist-provided MTM services, and/or the current public health priority focused on addressing the opioid epidemic.

The current study found that some providers deprescribed (either an opioid or benzodiazepine), yet the reasons for doing so are not well understood. Another study found that a direct-to-provider intervention reduced opioid dosing and significantly decreased co-prescribing of opioids with benzodiazepines [10]. However, identifying effective strategies to urge prescribers to dose reduce and/or deprescribe opioids and benzodiazepines is not without its challenges. Barriers still remain such 
as employing effective communication channels to ensure receipt of the pharmacist's recommendations, prescriber knowledge regarding patients' risk for adverse drug events, and lack of resources and institutional support for deprescribing and providing viable alternatives [18].

However, some patients still may resist deprescribing if they feel the health condition that they were using drugs to manage is critical to effective symptom management and their current treatment. In a recent study, patients expressed healthcare system factors and positive personal experiences with sedative medication usage as reasons for disputing providers' recommendation to deprescribe while being concerned about safe alternatives [18]. Yet, numerous, viable alternatives exist rather than relying on co-prescribing opioids and benzodiazepines. For example, previous studies have found that individuals with chronic pain effectively use a variety of strategies to manage it, including both pharmacological and non-pharmacological approaches [19]. Furthermore, another study found that pharmacists with chronic pain used a mean of $13 \pm 5$ pharmacological and non-pharmacological management strategies, while some used as many as 31 different ones [20]. Additionally, direct-to-patient educational interventions may provide promising opportunities, especially when coupled with individualized care [18].

There were limitations with this study. First, it used a prescription claims database, and thus it was impossible to determine whether the medication was actually taken, if prescriptions were purchased with cash or obtained from a prescriber beyond their primary provider, or if the patient was non-compliant with prescription discontinuation and continued to take medications on-hand thereafter. Second, while the sample size was large, limited details such as a verbal or written response from the provider to the pharmacist recommendation, were available beyond whether an intervention was made and accepted. Third, this study used a sample of Medicare beneficiaries, and thus the generalizability is limited to this population. Fourth, the study had a relatively short follow-up period of 120 days, limiting its generalizability. Lastly, lack of information on the number of alerts compared to total recommendations may have contributed bias in the study regarding provider acceptance rates. Further investigation is warranted to study whether pharmacist interventions are effective in reducing co-prescription of opioids and other potentiator medications as well as exploring if deprescribing rates are maintainable over a longer study period ( $>4$ months).

\section{Conclusions}

This study involving prescription claims data described the characteristics of patients and the most commonly co-prescribed opioids and benzodiazepines discontinued following a pharmacistdelivered, direct-to-provider intervention. These study findings suggest that pharmacist-initiated, direct-to-prescriber communication may help reduce co-prescribing of opioids and benzodiazepines in a Medicare population. However, more work is needed, using a more comprehensive data source and analytical study design, to investigate types of pharmacist interventions made and intervention types accepted by providers. Further research is warranted to evaluate whether these same results are achievable with opioids and other potentiator medications, and to investigate this pharmacist-delivered medication therapy management program in more diverse populations and settings.

Author Contributions: Conceptualization J.M.B. and K.P.B.; validation, D.R.A.; formal analysis, D.R.A.; investigation, J.M.B. and D.R.A.; resources, J.M.B., A.M.T., and D.R.A.; data curation, K.P.B. and J.M.B.; writing-original draft preparation, J.M.B., D.R.A., and A.M.T.; writing-review and editing, K.P.B, A.M.T, J.M.B, and D.R.A.; supervision, J.M.B.; project administration, J.M.B. All authors have read and agreed to the published version of the manuscript.

Funding: The research received no external funding.

Conflicts of Interest: Ann M. Taylor and David R. Axon received funding from SinfoníaRx. Ann M. Taylor received funding from the Arizona Department of Health Services. Jennifer M. Bingham has disclosed an outside interest in Tabula Rasa HealthCare to the University of Arizona. Kevin P. Boesen is employed by Tabula Rasa HealthCare. Conflicts of interest resulting from this interest are being managed by The University of Arizona in accordance with its policies. The other authors did not receive any specific grant from funding agencies in the public, commercial, or not-for-profit sectors for this study. 


\section{Appendix A}

Table A1. List of opioid medications co-prescribed with benzodiazepine medications $(N=57,748)$.

\begin{tabular}{|c|c|c|}
\hline Opioid Name & $N$ & $\%$ \\
\hline ABSTRAL & 1 & 0.00 \\
\hline ACETAMIN-CAFF-DIHYDROCODEINE & 1 & 0.00 \\
\hline ACETAMINOPHEN-CODEINE & 2640 & 4.57 \\
\hline ARYMO ER & 2 & 0.00 \\
\hline ASCOMP WITH CODEINE & 12 & 0.02 \\
\hline BELBUCA & 33 & 0.06 \\
\hline BUPRENORPHINE & 70 & 0.12 \\
\hline BUTALB-ACETAMINOPH-CAFF-CODEINE & 35 & 0.06 \\
\hline BUTALB-CAFF-ACETAMINOPH-CODEINE & 36 & 0.06 \\
\hline BUTALBITAL COMPOUND-CODEINE & 34 & 0.06 \\
\hline BUTORPHANOL TARTRATE & 38 & 0.07 \\
\hline BUTRANS & 307 & 0.53 \\
\hline CARISOPRODOL-ASPIRIN-CODEINE & 1 & 0.00 \\
\hline CODEINE SULFATE & 27 & 0.05 \\
\hline CONZIP & 2 & 0.00 \\
\hline DEMEROL & 5 & 0.01 \\
\hline DILAUDID & 22 & 0.04 \\
\hline DURAGESIC & 30 & 0.05 \\
\hline EMBEDA & 41 & 0.07 \\
\hline ENDOCET & 290 & 0.50 \\
\hline EXALGO & 8 & 0.01 \\
\hline FENTANYL & 1945 & 3.37 \\
\hline FENTANYL CITRATE & 7 & 0.01 \\
\hline FIORICET WITH CODEINE & 2 & 0.00 \\
\hline FIORINAL WITH CODEINE \#3 & 10 & 0.02 \\
\hline HYDROCODONEBT-HOMATROPINE MBR & 1 & 0.00 \\
\hline HYDROCODONE-ACETAMINOPHEN & 19,401 & 33.60 \\
\hline HYDROCODONE-CHLORPHENIRAMNE ER & 143 & 0.25 \\
\hline HYDROCODONE-HOMATROPINE MBR & 91 & 0.16 \\
\hline HYDROCODONE-IBUPROFEN & 60 & 0.10 \\
\hline HYDROMET & 49 & 0.08 \\
\hline HYDROMORPHONE ER & 62 & 0.11 \\
\hline HYDROMORPHONE HCL & 837 & 1.45 \\
\hline HYSINGLA ER & 63 & 0.11 \\
\hline IBUDONE & 1 & 0.00 \\
\hline KADIAN & 6 & 0.01 \\
\hline LEVORPHANOL TARTRATE & 8 & 0.01 \\
\hline LORCET & 6 & 0.01 \\
\hline LORCET HD & 9 & 0.02 \\
\hline LORCET PLUS & 3 & 0.01 \\
\hline LORTAB & 11 & 0.02 \\
\hline MEPERIDINE HCL & 23 & 0.04 \\
\hline METHADONE HCL & 501 & 0.87 \\
\hline METHADONE INTENSOL & 1 & 0.00 \\
\hline METHADOSE & 1 & 0.00 \\
\hline MORPHABOND ER & 1 & 0.00 \\
\hline MORPHINE SULFATE & 553 & 0.96 \\
\hline MORPHINE SULFATE ER & 2014 & 3.49 \\
\hline MS CONTIN & 3 & 0.01 \\
\hline NORCO & 78 & 0.14 \\
\hline NUCYNTA & 135 & 0.23 \\
\hline NUCYNTA ER & 105 & 0.18 \\
\hline OPANA & 6 & 0.01 \\
\hline
\end{tabular}


Table A1. Cont.

\begin{tabular}{|c|c|c|}
\hline Opioid Name & $N$ & $\%$ \\
\hline OPANA ER & 91 & 0.16 \\
\hline OXAYDO & 4 & 0.01 \\
\hline OXYCODONE HCL & 5349 & 9.26 \\
\hline OXYCODONE HCL ER & 336 & 0.58 \\
\hline OXYCODONE HCL-ASPIRIN & 11 & 0.02 \\
\hline OXYCODONE HCL-IBUPROFEN & 1 & 0.00 \\
\hline OXYCODONE-ACETAMINOPHEN & 9045 & 15.66 \\
\hline OXYCONTIN & 1203 & 2.08 \\
\hline OXYMORPHONE HCL & 82 & 0.14 \\
\hline OXYMORPHONE HCL ER & 299 & 0.52 \\
\hline PERCOCET & 113 & 0.20 \\
\hline PROMETHAZINE-CODEINE & 408 & 0.71 \\
\hline ROXICODONE & 9 & 0.02 \\
\hline SUBSYS & 7 & 0.01 \\
\hline TRAMADOL HCL & 10,107 & 17.50 \\
\hline TRAMADOL HCL ER & 207 & 0.36 \\
\hline TRAMADOL HCL-ACETAMINOPHEN & 424 & 0.73 \\
\hline TREZIX & 1 & 0.00 \\
\hline TUSSIGON & 1 & 0.00 \\
\hline TUSSIONEX & 11 & 0.02 \\
\hline TUZISTRA XR & 1 & 0.00 \\
\hline TYLENOL-CODEINE NO.3 & 32 & 0.06 \\
\hline TYLENOL-CODEINE NO.4 & 3 & 0.01 \\
\hline ULTRACET & 12 & 0.02 \\
\hline ULTRAM & 22 & 0.04 \\
\hline VICODIN & 61 & 0.11 \\
\hline VICODIN ES & 31 & 0.05 \\
\hline VICODIN HP & 12 & 0.02 \\
\hline VITUZ & 2 & 0.00 \\
\hline XARTEMIS XR & 2 & 0.00 \\
\hline XODOL 7.5-300 & 1 & 0.00 \\
\hline XTAMPZA ER & 48 & 0.08 \\
\hline ZOHYDRO ER & 41 & 0.07 \\
\hline
\end{tabular}

Note: Bold font indicates the top five opioid medications.

Table A2. List of benzodiazepine medications co-prescribed with opioid medications $(N=57,748)$.

\begin{tabular}{ccc}
\hline Benzodiazepine Name & $N$ & $\mathbf{\%}$ \\
\hline ALPRAZOLAM & $\mathbf{2 0 , 2 7 5}$ & $\mathbf{3 5 . 1 1}$ \\
ALPRAZOLAM ER & 132 & 0.23 \\
ALPRAZOLAM ODT & 35 & 0.06 \\
ALPRAZOLAM XR & 75 & 0.13 \\
ATIVAN & 118 & 0.20 \\
CHLORDIAZEPOXIDE HCL & 154 & 0.27 \\
CHLORDIAZEPOXIDE-AMITRIPTYLINE & 40 & 0.07 \\
CHLORDIAZEPOXIDE-CLIDINIUM & 121 & 0.21 \\
CLONAZEPAM & $\mathbf{1 2 , 2 2 2}$ & $\mathbf{2 1 . 1 6}$ \\
CLORAZEPATE DIPOTASSIUM & 475 & 0.82 \\
DIAZEPAM & $\mathbf{6 9 8 8}$ & $\mathbf{1 2 . 1 0}$ \\
ESTAZOLAM & 43 & 0.07 \\
FLURAZEPAM HCL & 77 & 0.13 \\
HALCION & 11 & 0.02 \\
KLONOPIN & 58 & 0.10 \\
LIBRAX & 54 & 0.09 \\
\hline
\end{tabular}


Table A2. Cont.

\begin{tabular}{ccc}
\hline Benzodiazepine Name & $N$ & $\mathbf{\%}$ \\
\hline LORAZEPAM & $\mathbf{1 1 , 5 9 9}$ & $\mathbf{2 0 . 0 9}$ \\
LORAZEPAM INTENSOL & 14 & 0.02 \\
NIRAVAM & 1 & 0.00 \\
ONFI & 14 & 0.02 \\
OXAZEPAM & 150 & 0.26 \\
RESTORIL & 38 & 0.07 \\
TEMAZEPAM & $\mathbf{4 2 3 3}$ & $\mathbf{7 . 3 3}$ \\
TRANXENE T-TAB & 3 & 0.01 \\
TRIAZOLAM & 300 & 0.52 \\
VALIUM & 139 & 0.24 \\
XANAX & 372 & 0.64 \\
XANAX XR & 7 & 0.01 \\
\hline
\end{tabular}

Bold font indicates the top five benzodiazepine medications.

Table A3. Medications discontinued by prescriber following pharmacist recommendations aimed to reduce co-prescribing of opioid and benzodiazepine medications $(N=37,990)$.

\begin{tabular}{|c|c|c|}
\hline Pharmacist Recommendation to Prescriber to Remove: & $N$ & $\%$ \\
\hline ACETAMIN-CAFF-DIHYDROCODEINE & 1 & 0.00 \\
\hline ACETAMINOPHEN-CODEINE & 1698 & 4.47 \\
\hline ALPRAZOLAM & 5390 & 14.19 \\
\hline ALPRAZOLAM ER & 40 & 0.11 \\
\hline ALPRAZOLAM ODT & 20 & 0.05 \\
\hline ALPRAZOLAM XR & 37 & 0.10 \\
\hline ASCOMP WITH CODEINE & 6 & 0.02 \\
\hline ATIVAN & 6 & 0.02 \\
\hline BELBUCA & 9 & 0.02 \\
\hline BUPRENORPHINE & 37 & 0.10 \\
\hline BUTALB-ACETAMINOPH-CAFF-CODEINE & 13 & 0.03 \\
\hline BUTALB-CAFF-ACETAMINOPH-CODEINE & 15 & 0.04 \\
\hline BUTALBITAL COMPOUND-CODEINE & 12 & 0.03 \\
\hline BUTORPHANOL TARTRATE & 14 & 0.04 \\
\hline BUTRANS & 151 & 0.40 \\
\hline CARISOPRODOL-ASPIRIN-CODEINE & 1 & 0.00 \\
\hline CHLORDIAZEPOXIDE HCL & 61 & 0.16 \\
\hline CHLORDIAZEPOXIDE-AMITRIPTYLINE & 5 & 0.01 \\
\hline CHLORDIAZEPOXIDE-CLIDINIUM & 67 & 0.18 \\
\hline CLONAZEPAM & 2412 & 6.35 \\
\hline CLORAZEPATE DIPOTASSIUM & 147 & 0.39 \\
\hline CODEINE SULFATE & 13 & 0.03 \\
\hline DIAZEPAM & 2227 & 5.86 \\
\hline DILAUDID & 2 & 0.01 \\
\hline DURAGESIC & 3 & 0.01 \\
\hline EMBEDA & 13 & 0.03 \\
\hline ENDOCET & 94 & 0.25 \\
\hline ESTAZOLAM & 6 & 0.02 \\
\hline EXALGO & 2 & 0.01 \\
\hline FENTANYL & 420 & 1.11 \\
\hline FENTANYL CITRATE & 1 & 0.00 \\
\hline FIORINAL WITH CODEINE \#3 & 1 & 0.00 \\
\hline FLURAZEPAM HCL & 28 & 0.07 \\
\hline HALCION & 1 & 0.00 \\
\hline HYDROCODONE-ACETAMINOPHEN & 7165 & 18.86 \\
\hline HYDROCODONE-CHLORPHENIRAMNE ER & 113 & 0.30 \\
\hline HYDROCODONE-HOMATROPINE MBR & 70 & 0.18 \\
\hline
\end{tabular}


Table A3. Cont.

\begin{tabular}{|c|c|c|}
\hline Pharmacist Recommendation to Prescriber to Remove: & $N$ & $\%$ \\
\hline HYDROCODONE-IBUPROFEN & 32 & 0.08 \\
\hline HYDROMET & 40 & 0.11 \\
\hline HYDROMORPHONE ER & 17 & 0.04 \\
\hline HYDROMORPHONE HCL & 359 & 0.94 \\
\hline HYSINGLA ER & 22 & 0.06 \\
\hline IBUDONE & 1 & 0.00 \\
\hline KADIAN & 6 & 0.02 \\
\hline KLONOPIN & 8 & 0.02 \\
\hline LEVORPHANOL TARTRATE & 3 & 0.01 \\
\hline LIBRAX & 20 & 0.05 \\
\hline LORAZEPAM & 3547 & 9.34 \\
\hline LORAZEPAM INTENSOL & 12 & 0.03 \\
\hline LORCET & 3 & 0.01 \\
\hline LORCET HD & 7 & 0.02 \\
\hline LORCET PLUS & 2 & 0.01 \\
\hline LORTAB & 2 & 0.01 \\
\hline MEPERIDINE HCL & 10 & 0.03 \\
\hline METHADONE HCL & 97 & 0.26 \\
\hline METHADONE INTENSOL & 1 & 0.00 \\
\hline MORPHINE SULFATE & 235 & 0.62 \\
\hline MORPHINE SULFATE ER & 446 & 1.17 \\
\hline MS CONTIN & 1 & 0.00 \\
\hline NORCO & 10 & 0.03 \\
\hline NUCYNTA & 60 & 0.16 \\
\hline NUCYNTA ER & 43 & 0.11 \\
\hline OPANA & 5 & 0.01 \\
\hline OPANA ER & 60 & 0.16 \\
\hline OXAYDO & 1 & 0.00 \\
\hline OXAZEPAM & 27 & 0.07 \\
\hline OXYCODONE HCL & 1604 & 4.22 \\
\hline OXYCODONE HCL ER & 162 & 0.43 \\
\hline OXYCODONE HCL-ASPIRIN & 4 & 0.01 \\
\hline OXYCODONE HCL-IBUPROFEN & 1 & 0.00 \\
\hline OXYCODONE-ACETAMINOPHEN & 3365 & 8.86 \\
\hline OXYCONTIN & 261 & 0.69 \\
\hline OXYMORPHONE HCL & 23 & 0.06 \\
\hline OXYMORPHONE HCL ER & 82 & 0.22 \\
\hline PERCOCET & 18 & 0.05 \\
\hline PROMETHAZINE-CODEINE & 323 & 0.85 \\
\hline RESTORIL & 3 & 0.01 \\
\hline SUBSYS & 1 & 0.00 \\
\hline TEMAZEPAM & 1095 & 2.88 \\
\hline TRAMADOL HCL & 5131 & 13.51 \\
\hline TRAMADOL HCL ER & 65 & 0.17 \\
\hline TRAMADOL HCL-ACETAMINOPHEN & 235 & 0.62 \\
\hline TREZIX & 1 & 0.00 \\
\hline TRIAZOLAM & 63 & 0.17 \\
\hline TUSSIONEX & 2 & 0.01 \\
\hline TUZISTRA XR & 1 & 0.00 \\
\hline TYLENOL-CODEINE NO.3 & 3 & 0.01 \\
\hline ULTRACET & 4 & 0.01 \\
\hline ULTRAM & 6 & 0.02 \\
\hline VALIUM & 22 & 0.06 \\
\hline VICODIN & 43 & 0.11 \\
\hline VICODIN ES & 16 & 0.04 \\
\hline VICODIN HP & 8 & 0.02 \\
\hline XANAX & 34 & 0.09 \\
\hline
\end{tabular}


Table A3. Cont.

\begin{tabular}{ccc}
\hline Pharmacist Recommendation to Prescriber to Remove: & $N$ & $\%$ \\
\hline XANAX XR & 4 & 0.01 \\
XARTEMIS XR & 2 & 0.01 \\
XODOL 7.5-300 & 1 & 0.00 \\
XTAMPZA ER & 21 & 0.06 \\
ZOHYDRO ER & 8 & 0.02 \\
\hline
\end{tabular}

Note: Bold font indicates the top five medications removed by the prescriber in response to recommendations made by the pharmacist to reduce co-prescribing of opioid and benzodiazepine medications.

\section{References}

1. Steinman, M.A.; Komaiko, K.D.R.; Fung, K.Z.; Ritchie, C.S. Use of opioids and other analgesics by older adults in the United States, 1999-2010. Pain Med. 2015, 16, 319-327. [CrossRef] [PubMed]

2. Gomes, T.; Tadrous, M.; Mamdani, M.M.; Paterson, J.M.; Juurlink, D.N. The Burden of Opioid-Related Mortality in the United States. JAMA Netw. Open 2018, 1, e180217. [CrossRef] [PubMed]

3. Wu, T.-Z.; Ghitza, U.E.; Burns Al Mannelli, P. The opioid overdose epidemic: Opportunities for pharmacists. Subst. Abus. Rehabil. 2017, 8, 53-55. [CrossRef] [PubMed]

4. Martin, L.; Laderman, M.; Hyatt, J.; Krueger, J. Addressing the Opioid Crisis in the United States; IHI Innovation Report; Institute for Healthcare Improvement: Cambridge, MA, USA, 2016. Available online: http: //www.ihi.org/resources/Pages/Publications/Addressing-Opioid-Crisis-US.aspx (accessed on 19 February 2020).

5. Murdaugh, L.B. Competence Assessment Tools for Health-System Pharmacies, 4th ed.; Amer Soc Hlth-Sys Pharm.: Bethesda, MD, USA, 2008. Available online: http://tinyurl.com/6jadyhz (accessed on 19 February 2020).

6. Dowell, D.; Haegerich, T.M.; Chou, R. CDC guideline for prescribing opioids for chronic pain-United States, 2016. MMWR Recomm. Rep. 2016, 65, 1-49. [CrossRef] [PubMed]

7. Park, T.W.; Saitz, R.; Ganoczy, D.; Ilgen, M.A.; Bohnert, A.S. Benzodiazepine prescribing patterns and deaths from drug overdose among US veterans receiving opioid analgesics: case-cohort study. BMJ 2015, 350, h2698. [CrossRef]

8. Hwang, C.S.; Kang, E.M.; Kornegay, C.J.; Staffa, J.A.; Jones, C.M.; McAninch, J.K. Trends in the concomitant prescribing of opioids and benzodiazepines, 2002-2014. Am. J. Prev. Med. 2016, 51, 151-160. [CrossRef] [PubMed]

9. Cox, N.; Tak, C.R.; Cochella, S.E.; Leishman, E.; Gunning, K. Impact of pharmacist previsit input to providers on chronic opioid prescribing safety. J. Am. Board. Fam. Med. 2018, 31, 105-112. [CrossRef] [PubMed]

10. Brummel, A.; Lustig, A.; Westrich, K.; Evans, M.A.; Plank, G.S.; Penso, J.; Dubois, R.W. Best practices: improving patient outcomes and costs in an ACO through comprehensive medication therapy management. J. Manag. Care Spec. Pharm. 2014, 20, 1152-1158. [CrossRef]

11. Green, T.C.; Dauria, E.F.; Bratberg, J.; Davis, C.S.; Walley, A.Y. Orienting patients to greater opioid safety: models of community pharmacy-based naloxone. Harm Reduct. J. 2015, 12, 25. [CrossRef] [PubMed]

12. American Society of Health-System Pharmacists (ASHP). ASHP statement on the pharmacist's role in substance abuse prevention, education, and assistance. Am. J. Health Syst. Pharm. 2014, 71, 243-246. [CrossRef] [PubMed]

13. Bain, K.; Knowlton, C. Role of opioid-Involved Drug Interactions in Chronic Pain Management. J. Am. Osteopath Assoc. 2019, 119, 839-847. [CrossRef] [PubMed]

14. Monane, M.; Matthias, D.M.; Nagle, B.A.; Kelly, M.A. Improving prescribing patterns for the elderly through an online drug utilization review intervention: A system linking the physician, pharmacist, and computer. JAMA 1998, 280, 1249-1252. [CrossRef] [PubMed]

15. Taylor, A.M.; Bingham, J.; Schussel, K.; Axon, D.R.; Dickman, D.J.; Boesen, K.; Martin, R.; Warholak, T. Integrating innovative telehealth solutions into an interprofessional team-delivered chronic care management pilot program. J. Manag. Care Spec. Pharm. 2018, 24, 813-818. [CrossRef] [PubMed]

16. Michaels, N.M.; Jenkins, G.F.; Pruss, D.L.; Heidrick, J.E.; Ferreri, S.P. Retrospective analysis of community pharmacists' recommendations in the North Carolina Medicaid medication therapy management program. J. Am. Pharm. Assoc. 2010, 50, 347-353. [CrossRef] [PubMed] 
17. Perera, P.N.; Guy, M.C.; Sweaney, A.M.; Boesen, K.P. Evaluation of prescriber responses to pharmacist recommendations communicated by fax in a medication therapy management program (MTMP). J. Manag. Care Spec. Pharm. 2011, 17, 345-354. [CrossRef]

18. Kuntz, J.; Kouch, L.; Christian, D.; Peterson, P.L.; Gruss, I. Barriers and Facilitators to the Deprescribing of Nonbenzodiazepine Sedative Medications Among Older Adults. Perm J. 2018, 22, 17-157. [CrossRef] [PubMed]

19. Axon, D.R.; Patel, M.J.; Martin, J.R.; Slack, M.K. Use of multidomain management strategies by community dwelling adults with chronic pain: Evidence from a systematic review. Scand. J. Pain. 2019, 19, 9-23. [CrossRef] [PubMed]

20. Axon, D.R.; Bhattacharjee, S.; Warholak, T.L.; Slack, M.K. Xm2 scores for estimating total exposure to multimodal strategies identified by pharmacists for managing pain: Validity testing and clinical relevance. Pain Res. Manag. 2018. [CrossRef] [PubMed]

(C) 2020 by the authors. Licensee MDPI, Basel, Switzerland. This article is an open access article distributed under the terms and conditions of the Creative Commons Attribution (CC BY) license (http://creativecommons.org/licenses/by/4.0/). 